\title{
Trichoderma spp NO BIOCONTROLE DE Cylindrocladium candelabrum EM MUDAS DE Eucalyptus saligna ${ }^{1}$
}

Caciara Gonzatto $\mathrm{Maciel}^{2}, \mathrm{Mar}_{1}$ ia Lazarotto ${ }^{3}, \mathrm{Ricardo}_{\mathrm{Mezzomo}}$, Igor Poletto ${ }^{4}$, Marlove Fátima Brião Muniz $^{5}$ e Diogo Belmonte Lippert ${ }^{3}$

\begin{abstract}
RESUMO - Este trabalho teve como objetivo testar os efeitos in vitro e in vivo de bioprotetores à base de Trichoderma spp. no controle do fungo Cylindrocladium candelabrum Viegas. Os testes in vitro (confronto direto e inoculação em folhas destacadas) foram compostos pelos seguintes tratamentos: $\mathrm{T}_{1}$ - somente $C$. candelabrum; $\mathrm{T}_{2}$ - isolado $06006 \mathrm{~S}$ x C. candelabrum; $\mathrm{T}_{3}$ - isolado 53RR x C. candelabrum; $\mathrm{T}_{4}$ - isolado 5D x C. candelabrum; $\mathrm{T}_{5}$ - Agrotrich ${ }^{\circledR}$ x C. candelabrum; $\mathrm{e}_{6}$ - Trichode $\mathrm{l}^{\circledR} \mathrm{x}$ C. candelabrum. Todos os tratamentos foram eficientes inibindo o crescimento do fungo C. candelabrum em confrontação direta, e os isolados de Trichoderma spp. 53RR e 06006S, bem como o produto comercial Trichodel ${ }^{\circledR}$, controlaram a mancha-foliar em folhas destacadas. Para complementar os testes in vitro, os produtos comerciais Agrotrich ${ }^{\circledR} \mathrm{e}^{\text {Trichodel }}{ }^{\circledR}$ foram testados em mudas de E. saligna cultivadas em casa de vegetação, com os seguintes tratamentos: $\mathrm{T}_{1-}$ Testemunha: sem inoculação; $\mathrm{T}_{2}$ - inoculação de C. candelabrum; $\mathrm{T}_{3}$ - inoculação de C. candelabrum $\mathrm{x}$

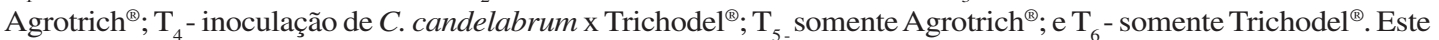
produto apresentou os melhores resultados na redução dos danos causados pelo patógeno em mudas de E. saligna.
\end{abstract}

Palavras-chave: Bioprotetores, Fungo e Mancha-foliar.

\section{CONTROL OF Cylindrocladium candelabrum BY Trichoderma spp IN Eucalyptus saligna SEEDLINGS}

\begin{abstract}
This study tested the effects of commercial biocontrol products on in vitro and in vivo trials against the fungal pathogen Cylindrocladium candelabrum Viegas, leaf blight agent on Eucalyptus saligna. The in vitro tests (direct confrontation and inoculation on detached leaves of $\boldsymbol{E}$. saligna) were composed by the following treatments: $T_{1}-$ only $\boldsymbol{C}$. candelabrum, $T_{2}-06006 S$ isolate $x \boldsymbol{C}$. candelabrum, $T_{3}-53 R R$ isolate $x$ C. candelabrum, $T_{4}-5 D$ isolate $x$ C. candelabrum; $T_{5}-$ Agrotrich $^{\circledR} x$ C. candelabrum and $T_{6}$ - Trichodel ${ }^{\circledR} x$ C. candelabrum. All isolates were efficient in controlling the growth of the pathogen during the direct confrontation test; similarly, Trichoderma spp. 53RR and 06006S, as well as the commercial product Trichodel ${ }^{\circledR}$, controlled the symptoms on the detached leaves. In order to complement the in vitro tests, the commercial products Agrotrich $^{\circledR}$ and Trichodel ${ }^{\circledR}$ were tested on $\boldsymbol{E}$. saligna seedlings cultivated in greenhouse. The following treatments were applied: $T_{1-}$ control - plants without inoculation; $T_{2}$ - plants inoculated with C. candelabrum; $T_{3}$-plants inoculated with C. candelabrum $x$ Agrotrich ${ }^{\circledast} ; T_{4}-$ plants inoculated with

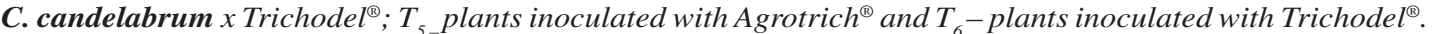
Trichode $l^{\circledR}$ reduced . candelabrum damage on $\mathrm{E}$. saligna seedlings.
\end{abstract}

Keywords: Bioprotectors, Fungus and Leaf spot.

\footnotetext{
${ }^{1}$ Recebido em 30.08.2011 aceito para publicação em 04.06.2012.

${ }^{2}$ Mestrado na Universidade Federal de Santa Maria, Departamento de Defesa Fitossanitária, UFSM.E-mail:<caciaragonzatto@ gmail.com>.

${ }^{3}$ Programa de Pós-Graduação em Engenharia Florestal pela Universidade Federal de Santa Maria, Departamento de Defesa Fitossanitária, UFSM. E-mail: <lilalazarotto@yahoo.com.br>, <ricadom@gmail.com>e <diogo_b_lippert@ @otmail.com>. ${ }^{4}$ Universidade Federal do Pampa. E-mail: <igorpoletto@yahoo.com.br>.

${ }^{5}$ Universidade Federal de Santa Maria, Centro de Ciências Rurais, Departamento de Defesa Fitossanitária, UFSM. E-mail: <marlovemuniz@yahoo.com.br>.
} 


\section{INTRODUÇÃO}

A clonagem por miniestaquia vem sendo adotada na maioria das empresas do setor florestal. Embora essa técnica seja muito eficiente, durante a fase de enraizamento das miniestacas ocorre a incidência de patógenos devido às condições ambientais propícias. Segundo Ferreira (2006), as miniestacas são mantidas em condições de elevada umidade e temperatura amena durante 20 a 25 dias na casa de enraizamento. Nessas condições é comum a ocorrência de fungos fitopatogênicos como Botrytis cinerea Pers., Cylindrocladium spp., Rhizoctonia spp., Pestalotiopsis sp. e Hainesia sp.

Entre as muitas espécies de Cylindrocladium que frequentemente causam doenças em viveiros no Brasil, C. candelabrum apresenta alta ocorrência. Esse fungo é um dos principais responsáveis por doenças em mudas de eucalipto, como podridão-de-estacas, "dampingoff” e manchas-foliares (ALFENAS et al., 2004).

A mancha-foliar em mudas de eucalipto, causada por Cylindrocladium, ocasiona necrose nas folhas, afetando o desenvolvimento da plântula. Dessa maneira, torna-a incapacitada de resistir às condições de campo. Essas lesões são caracterizadas como manchas acinzentadas, circulares a alongadas, individuais e pequenas (1 a $7 \mathrm{~mm}$ de diâmetro) (FERREIRA et al., 1992). Em estágios avançados, verificou-se a presença de micélio cotonoso (CARVALHO FILHO, 2008).

O uso de antagonistas biológicos como Trichoderma spp. tem apresentado bons resultados no controle de fitopatógenos. Para Chet et al. (1997), o sucesso no uso de espécies de Trichoderma se deve à sua alta capacidade reprodutiva, habilidade de sobreviver em condições desfavoráveis, eficiência na mobilização e na absorção de nutrientes, eficácia como promotor de enraizamento de plântulas e agressividade contra fungos patogênicos. Quanto à ação benéfica de Trichoderma spp. em manchas-foliares, pode-se citar o controle de Pythium sp. (NASEBY et al., 2000) e de Cilindrocladium spathulatum em erva-mate (GOMES et al., 2001).

Bioprotetores comerciais à base de Trichoderma spp. estão sendo utilizados em larga escala, entre eles o Agrotrich ${ }^{\circledR}$ e o Trichodel ${ }^{\circledR}$. O primeiro é um agente biológico que se apresenta como um pó, que pode ser aplicado via substrato, semente, adubo ou via solo. Já o Trichodel ${ }^{\circledR}$ se apresenta na forma líquida e deve ser incorporado ao substrato utilizado.
Testes complementares em laboratório, como confronto direto e avaliação de severidade em folhas destacadas, são de grande importância para a seleção de isolados de Trichoderma spp. ativos no controle de fungos fitopatôgenicos. Carvalho Filho (2008) encontrou cinco isolados de Trichoderma spp. compatíveis com o controle de C. scoparium quando testados no cultivo pareado e na supressão da mancha em folhas destacadas de Eucalyptus urophylla.

Diante do exposto, este trabalho teve por objetivos testar a eficiência in vitro de bioprotetores comerciais e isolados de Trichoderma spp. com potencial antagonista ao fungo $C$. candelabrum e avaliar a capacidade de ação in vivo dos bioprotetores comerciais no controle de C. candelabrum em mudas de Eucalyptus saligna.

\section{MATERIAL E MÉTODOS}

Os experimentos in vitro foram realizados no Laboratório de Fitopatologia do Departamento de Defesa Fitossanitária, no Centro de Ciências Rurais da Universidade Federal de Santa Maria (UFSM), em Santa Maria, RS. A parte in vivo dos trabalhos foi realizada na Fundação Estadual de Pesquisa Agropecuária (FEPAGRO - Florestas), localizada em Santa Maria, RS.

\subsection{Isolados de Trichoderma spp. e Cylindrocladium candelabrum}

O isolado de Cylindrocladium candelabrum foi fornecido pelo Laboratório de Patologia Florestal e Genética da Interação Planta-Patógeno da Universidade Federal de Viçosa, em Viçosa, MG.

Utilizaram-se três isolados (06006S, 53RR e 5D) de Trichoderma spp. disponíveis no banco de isolados do Laboratório de Fitopatologia da UFSM. Eles foram obtidos de diluições de solo rizosférico de plantas de soja com sintomas de podridão-vermelha-da-raiz (PVR) e dois produtos comerciais, Agrotrich ${ }^{\circledR}$ e Trichodel $^{\circledR}$.

\subsection{In vitro: avaliação da ação antagonista de Trichoderma spp. sobre Cylindrocladium candelabrum em confronto direto}

Neste estudo foram realizados testes de confronto direto com os seguintes tratamentos: $\mathrm{T}_{1}$ - somente $C$. candelabrum; $\mathrm{T}_{2}$ - isolado $06006 \mathrm{~S} \times$ C c candelabrum; $\mathrm{T}_{3}$ - isolado 53RR x C. candelabrum; $\mathrm{T}_{4}$ - isolado 5D x C. candelabrum; $\mathrm{T}_{5}$ - Agrotrich ${ }^{\circledR}$ x C. candelabrum; $\mathrm{e}_{6}$ - Trichode $^{\circledR}$ x C. candelabrum. Cada tratamento foi realizado com quatro repetições. 
Inicialmente, fez-se a multiplicação do patógeno e dos isolados de Trichoderma spp. em placas de Petri contendo meio BDA (batata-dextrose-ágar), incubadas a $25^{\circ} \mathrm{C}$ e com fotoperíodo de $12 \mathrm{~h}$, durante sete dias.

Um disco de $5 \mathrm{~mm}$ de diâmetro da cultura pura do patógeno foi retirado do centro da placa e transferido para uma placa contendo apenas BDA. Após 48 h, um disco do isolado de Trichoderma spp. de mesmo diâmetro, retirado do centro da placa crescida com cultura pura do antagonista, foi posicionado no lado oposto ao patógeno. As placas foram mantidas em incubadora a $25^{\circ} \mathrm{C}$ e com fotoperíodo de $12 \mathrm{~h}$, por sete dias.

A avaliação foi baseada na escala de Bell et al. (1982), que apresenta variação de notas de 1 a 5 . A nota 1 é atribuída quando o antagonista ocupa completamente a placa, suprimindo o patógeno; nota 2 , o antagonista invade no mínimo $2 / 3$ da superfície do meio; nota 3, a metade da placa é colonizada pelo antagonista e, a outra metade, pelo patógeno; nota 4, quando o patógeno coloniza no mínimo $2 / 3$ da superfície da placa; e nota 5 , quando o patógeno ocupa toda a placa, suprimindo o antagonista.

\subsection{In vitro: avaliação da supressão da mancha-foliar} de Cylindrocladium candelabrum por Trichoderma spp. em folhas destacadas de Eucalyptus saligna

O experimento dividiu-se em seis tratamentos: $T_{1}$ - somente C. candelabrum (testemunha); $\mathrm{T}_{2}$ - isolado 06006S x C. candelabrum; $\mathrm{T}_{3}$ - isolado 53RR x $C$. candelabrum; $\mathrm{T}_{4}$ - isolado $5 \mathrm{D} \times$ x . candelabrum $; \mathrm{T}_{5}$ - Agrotrich ${ }^{\circledR}$ x C. candelabrum; e $\mathrm{T}_{6}$ - Trichode $^{\circledR}$ x $C$. candelabrum. Cada tratamento foi realizado com duas repetições (caixas gerbox) contendo quatro folhas em cada caixa.

Para a produção da suspensão de Trichoderma spp., 50 g de grãos de arroz e $25 \mathrm{~mL}$ de água destilada foram colocados em erlenmeyers e esterilizados por duas vezes, com um intervalo de $24 \mathrm{~h}$, em autoclave a $120^{\circ} \mathrm{C}(1 \mathrm{~atm})$ por $1 \mathrm{~h}$. Em seguida, quatro discos de BDA de aproximadamente $12 \mathrm{~mm}$ de diâmetro, contendo micélio e, ou, esporos dos diferentes isolados, foram adicionados aos erlenmeyeres e incubados a $25^{\circ} \mathrm{C}$ e com fotoperíodo de $12 \mathrm{~h}$. Após 20 dias de crescimento, o arroz com Trichoderma spp. foi retirado dos erlenmeyers, colocado em envelopes de papel e levado ao forno a $30^{\circ} \mathrm{C}$, por aproximadamente $72 \mathrm{~h}$. Depois de secos, os grãos foram triturados em liquidificador até se tornarem pó, fino e homogêneo. Para o preparo da suspensão, a cada grama de pó foi adicionado $1 \mathrm{~mL}$ de água destilada.

Para a obtenção da suspensão de esporos de Cylindrocladium candelabrum, adicionaram-se $20 \mathrm{ml}$ de água destilada nas placas com a cultura fúngica (crescida por 10 dias em meio BDA), e raspou-se suavemente a superfície com um pincel. As contagens das concentrações de esporos dos isolados de Trichoderma spp. e do isolado de C. candelabrum foram realizadas em câmara de Neubauer e ajustadas para 7 x $10^{6}$ esporos.mL $L^{-1}$ e $10^{5}$ esporos.mL $L^{-1}$, respectivamente.

Para obtenção das suspensões de Trichoderma spp. a partir dos produtos comerciais Agrotrich ${ }^{\circledR} \mathrm{e}$ Trichodel $^{\circledR}$, usaram-se $1 \mathrm{~g}$ do produto por $100 \mathrm{~mL}$ de água e $1 \mathrm{~mL}$ do produto por $100 \mathrm{~mL}$ de água, respectivamente.

As folhas usadas no experimento foram retiradas de mudas de E. saligna cultivadas no viveiro da Universidade Federal de Santa Maria. Foram utilizadas folhas jovens, medindo aproximadamente $6,5 \mathrm{~cm}$ (comprimento) e 2,3 cm (largura) e livres de doenças. Estas foram lavadas com água esterilizada e dispostas sobre papel-filtro umedecido em caixas gerbox.

As folhas destacadas foram inoculadas com as suspensões de C. candelabrum e Trichoderma spp., mediante pulverizações com o auxílio de um pulverizador manual, de acordo com a metodologia proposta por Ferreira (2006). Patógeno e antagonista foram inoculados sequencialmente. Em seguida, as caixas gerbox foram vedadas e mantidas na temperatura ambiente.

Após cinco dias de inoculação, foram atribuídas notas para cada grau de severidade nas folhas destacadas de acordo com a escala proposta por Poletto (2008) e apresentada na Tabela 1 .

\subsection{In vivo: ação de agentes de controle biológico no controle da mancha-foliar causada por Cylindrocladium candelabrum em mudas de Eucalyptus saligna}

A partir dos resultados obtidos nos itens $2.2 \mathrm{e}$ 2.3 , testou-se o efeito in vivo dos produtos comerciais Agrotrich $^{\circledR} \mathrm{e} \mathrm{Trichodel}^{\circledR}$ no controle da mancha-foliar de C. candelabrum em E. saligna. Ambos os produtos

Revista Árvore, Viçosa-MG, v.36, n.5, p.825-832, 2012 
registrados comercialmente apresentaram resultados promissores na supressão do fungo $C$. candelabrum in vitro.

Os tratamentos utilizados foram: $\mathrm{T}_{1-}$ Testemunha, sem inoculação; $\mathrm{T}_{2}$ - inoculação de $C$. candelabrum; $\mathrm{T}_{3}$ - inoculação de C. candelabrum $\mathrm{x}$ Agrotrich ${ }^{\circledR} ; \mathrm{T}_{4}$ - inoculação de C. candelabrum $\times$ Trichodel ${ }^{\circledR} ; \mathrm{T}_{5-}$ somente Agrotrich $^{\circledR} ; \mathrm{e}_{6}$ - somente Trichodel ${ }^{\circledR}$. Cada tratamento foi constituído de quatro repetições com 25 mudas.

As mudas de Eucalyptus saligna utilizadas foram produzidas a partir de sementes que foram previamente desinfestadas em álcool (70\%) por 5 seg e solução de hipoclorito de sódio $(0,5 \%)$ por 30 seg e imediatamente lavadas com água destilada esterilizada. A semeadura foi realizada em tubetes suspensos mantidos em condições de viveiro nas instalações da FEPAGRO - Florestas. O substrato utilizado no experimento foi Argissolo Vermelho-Amarelo (STRECK et al., 2002) coletado no horizonte $\mathrm{A}(0-20 \mathrm{~cm})$, peneirado (malha $0,5 \mathrm{~cm}$ ) e seco à sombra. Os testes tiveram início quando as mudas, com quatro meses de idade, mediam aproximadamente $11 \mathrm{~cm}$, com diâmetro de colo médio de $0,4 \mathrm{~cm}$ e com 11 folhas.

Os bioprotetores foram aplicados via substrato: $1 \mathrm{~g}$ do produto. $100 \mathrm{~mL}^{-1}$ de água e $1 \mathrm{~mL}^{-1} \mathrm{do}$ produto. $100 \mathrm{~mL}^{-1}$ de água para Agrotrich ${ }^{\circledR} \mathrm{e}$ Trichodel ${ }^{\circledR}$, respectivamente. Ambos os produtos foram injetados nos primeiros $10 \mathrm{~cm}$ de substrato, com o auxílio de uma seringa manual, 10 dias antes da inoculação do patógeno.

As mudas foram inoculadas com a suspensão de esporos de C. candelabrum (produzida de acordo com a metodologia descrita no Item 2.3), mediante

Tabela 1 - Notas atribuídas aos graus de severidade causada por C. candelabrum em miniestacas de E. saligna

Table 1 -Rates given to the degree of severity caused by C. candelabrum in cuttings of E. saligna.

\begin{tabular}{cc}
\hline Notas* & Grau de severidade $(\%)$ \\
\hline 0 & Ausência de Sintoma \\
1 & 1 a 20 \\
2 & 21 a 40 \\
3 & 41 a 60 \\
4 & 61 a 80 \\
5 & 81 a 100 \\
\hline
\end{tabular}

*Em caso de variação da nota para mais ou para menos, no decorrer da avaliação optou-se pela nota maior. pulverizações (direcionadas preferencialmente para as folhas) com o auxílio de um pulverizador manual, de acordo com a metodologia proposta por Ferreira (2006).

Foram realizadas avaliações durante 60 dias, sendo a primeira aos 10 dias após a inoculação. Analisou-se, visualmente, o aparecimento de sintomas na parte aérea de cada muda. Foram atribuídas notas para cada grau de severidade, de acordo com escala proposta por Poletto (2008) e apresentada na Tabela 1.

Aos 60 dias foi contabilizado o número de folhas de cada muda e, com o auxílio de um paquímetro digital, foi determinada a altura da muda $(\mathrm{cm})$. A massa verde das mudas foi determinada com o auxílio de uma balança analítica com precisão de 0,01 g. Para isso, as mudas foram retiradas do substrato e suas raízes, lavadas em água corrente e pesadas. Para a determinação da biomassa seca $(\mathrm{g})$, as mudas foram acondicionadas em sacos de papel e levadas ao forno a uma temperatura de $70^{\circ} \mathrm{C}$ até atingir massa constante.

\subsection{Análise estatística}

Realizou-se a análise de variância dos experimentos, sendo as médias comparadas pelo teste de Tukey a $5 \%$ de probabilidade, utilizando o software SISVAR 5.3 (FERREIRA, 2010). Para análise dos resultados, os dados em porcentagem foram transformados em arcosseno da raiz quadrada $\left(\mathrm{x} \cdot 100^{-1}\right)$.

\section{RESULTADOS}

No teste de confrontação direta, os bioprotetores à base de Trichoderma spp. foram eficientes no controle do fungo $C$. candelabrum (Tabela 2). A relação antagonista de Trichoderma spp. sobre o patógeno recebeu notas que variaram de 1 a 2,25, correspondendo, respectivamente, à ocupação completa da placa pelo antagonista e antagonista ocupando no mínimo 2/3 da superfície do meio.

A utilização do teste em folhas destacadas complementou os resultados do teste in vitro, apresentado no item 2.3. Tanto os isolados de Trichoderma spp. quanto os compostos comerciais à base do antagonista foram eficientes na supressão da mancha-foliar em folhas destacadas, apresentando índices de severidade inferiores aos ocorridos na testemunha (Tabela 3). 
Tabela 2 - Eficiência dos isolados de Trichoderma spp. sobre Cylindrocladium candelabrum, de acordo com a escala de Bell et al. (1982) e a capacidade de crescimento (cm) do patógeno.

Table 2 - Efficiency of Trichoderma spp. on Cylindrocladium candelabrum, according to the scale of Bell et al. (1982) and growth capacity $(\mathrm{cm})$ of the pathogen.

\begin{tabular}{ccc}
\hline Tratamentos & Nota escala de Bell et al. (1982) & Crescimento C. candelabrum $(\mathrm{cm})$ \\
\hline $\mathrm{T}_{1}$ & $5,25 \mathrm{c} *$ & $5,3 \mathrm{~b}^{*}$ \\
$\mathrm{~T}_{2}$ & $1,25 \mathrm{ab}$ & $3,5 \mathrm{a}$ \\
$\mathrm{T}_{3}$ & $1,0 \mathrm{a}$ & $3,8 \mathrm{a}$ \\
$\mathrm{T}_{4}$ & $2,25 \mathrm{~b}$ & $3,43 \mathrm{a}$ \\
$\mathrm{T}_{5}$ & $1,5 \mathrm{ab}$ & $3,7 \mathrm{a}$ \\
$\mathrm{T}_{6}$ & $1,5 \mathrm{ab}$ & $3,3 \mathrm{a}$ \\
\hline
\end{tabular}

Tabela 3 - Efeito de Trichoderma spp. na supressão da manchafoliar causada por C. candelabrum em folhas destacadas de E. saligna.

Table 3 - Effect of Trichoderma spp. in the suppression of leaf spot caused by C. candelabrum in detached leaves of E. saligna.

\begin{tabular}{cc}
\hline Tratamentos & Severidade média $(\%)$ \\
\hline $\mathrm{T}_{1}$ & $73,4 \mathrm{a}^{*}$ \\
$\mathrm{~T}_{2}$ & $8,0 \mathrm{~b}$ \\
$\mathrm{~T}_{3}$ & $6,0 \mathrm{~b}$ \\
$\mathrm{~T}_{4}$ & $45,0 \mathrm{ab}$ \\
$\mathrm{T}_{5}$ & $40,0 \mathrm{ab}$ \\
$\mathrm{T}_{6}$ & $19,0 \mathrm{~b}$ \\
\hline
\end{tabular}

Em que: $\mathrm{T}_{1}$ - somente $C$. candelabrum (testemunha); $\mathrm{T}_{2}$ - isolado $06006 \mathrm{~S} \times$ C . candelabrum; $\mathrm{T}_{3}-$ isolado $53 \mathrm{RR} \times$ C . candelabrum; $\mathrm{T}_{4}$ - isolado 5D x C. candelabrum; $\mathrm{T}_{5}-$ Agrotrich $^{\circledR}$ x C. candelabrum; e $\mathrm{T}_{6}$ - Trichode ${ }^{\circledR} \mathrm{x} C$. candelabrum.

* Médias seguidas por mesma letra na coluna não diferem entre si, pelo teste de Tukey a 5\% de significância.

$\mathrm{O}$ isolado 53RR $\left(\mathrm{T}_{3}\right)$ foi o que apresentou menor índice de severidade (6\%), seguido do $06006 \mathrm{~S}$ $\left(\mathrm{T}_{2}, 8 \%\right)$ e do Trichodel ${ }^{\circledR}\left(\mathrm{T}_{6}, 19 \%\right)$. Os tratamentos com o isolado 5D $\left(\mathrm{T}_{4}\right)$ e com o Agrotrich ${ }^{\circledR}\left(\mathrm{T}_{5}\right)$ alcançaram graus de severidade de 45 e $40 \%$, respectivamente, não diferindo estatisticamente da testemunha $\left(\mathrm{T}_{1}, 73 \%\right)$.

No teste in vivo, observou-se que os tratamentos que não foram inoculados com o patógeno $\left(\mathrm{T}_{5}\right.$ e $\left.\mathrm{T}_{6}\right)$ não apresentaram qualquer sintoma da doença. Já nos tratamentos inoculados $\left(\mathrm{T}_{2}, \mathrm{~T}_{3}\right.$ e $\left.\mathrm{T}_{4}\right)$ a severidade da doença ficou bem evidente (Tabela 4).

Aos 45 dias após a inoculação, $\mathrm{T}_{2}$ (somente inoculação de C. candelabrum), seguido do $\mathrm{T}_{3}$

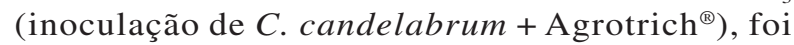
o que apresentou maior severidade nos sintomas
Tabela 4 - Porcentagem de mancha-foliar causada por Cylindrocladium candelabrum em mudas de Eucalyptus saligna.

Table 4-Percentage of leaf spot caused by Cylindrocladium candelabrum in Eucalyptus saligna seedlings.

\begin{tabular}{cccc}
\hline & \multicolumn{3}{c}{ Dias após a inoculação } \\
\cline { 2 - 4 } & 10 dias & 21 dias & 45 dias \\
\hline $\mathrm{T}_{1}$ & $0,0 \mathrm{a} *$ & $0,0 \mathrm{a}$ & $0,0 \mathrm{a}$ \\
$\mathrm{T}_{2}$ & $15,72 \mathrm{c}$ & $25,72 \mathrm{c}$ & $67,35 \mathrm{c}$ \\
$\mathrm{T}_{3}$ & $17,55 \mathrm{c}$ & $24,35 \mathrm{c}$ & $64,38 \mathrm{c}$ \\
$\mathrm{T}_{4}$ & $10,2 \mathrm{~b}$ & $18,5 \mathrm{~b}$ & $32,9 \mathrm{~b}$ \\
$\mathrm{~T}_{5}$ & $0,0 \mathrm{a}$ & $0,0 \mathrm{a}$ & $0,0 \mathrm{a}$ \\
$\mathrm{T}_{6}$ & $0,0 \mathrm{a}$ & $0,0 \mathrm{a}$ & $0,0 \mathrm{a}$ \\
\hline
\end{tabular}

$\mathrm{T}_{1}$ Testemunha - sem inoculação; $\mathrm{T}_{2}$ - inoculação de $C$. candelabrum; $\mathrm{T}_{3}$ - inoculação de $C$. candelabrum $\times$ Agrotrich ${ }^{\circledR} ; \mathrm{T}_{4}$ - inoculação de C. candelabrum $\times$ Trichodel ${ }^{\circledR} ; \mathrm{T}_{5}$ - somente Agrotrich $^{\circledR} ; \mathrm{e}_{6}$ somente Trichodel ${ }^{\circledR}$.

* Médias seguidas por mesma letra na coluna não diferem entre si, pelo teste de Tukey a 5\% de significância.

$(67,35 \%$ e $64,38 \%$, respectivamente) (Tabela 4$)$. As manchas-foliares eram de tamanhos irregulares e coloração roxa. Em estágios mais avançados, observou-se, no centro das lesões, o desenvolvimento de uma esporulação cristalina, característica do fungo.

$\mathrm{O} \mathrm{T}_{4}$ (inoculação de $C$. candelabrum + Trichodel $^{\circledR}$ ) foi o que apresentou menor porcentagem de área foliar atacada com a doença $(32,9 \%)$, diferindo estatisticamente dos demais.

A Tabela 5 apresenta os resultados de altura da muda, número de folhas, massa verde e massa seca. O tratamento sem inoculação de $C$. candelabrum e com adição de Trichodel ${ }^{\circledR}\left(\mathrm{T}_{6}\right)$ apresentou a massa verde (g) superior à dos demais, diferindo estatisticamente daqueles resultados.

Revista Árvore, Viçosa-MG, v.36, n.5, p.825-832, 2012 
Tabela 5 - Parâmetros avaliados em mudas de Eucalyptus saligna após diferentes tratamentos. Table 5 - Parameters evaluated in seedlings of Eucalyptus saligna after different treatments.

\begin{tabular}{|c|c|c|c|c|}
\hline \multirow[b]{2}{*}{ Tratamentos } & \multicolumn{4}{|c|}{ Parâmetros avaliados } \\
\hline & Altura da muda $(\mathrm{cm})$ & Número de folhas & Massa verde (g) & Massa seca $(\mathrm{g})$ \\
\hline $\mathrm{T}_{1}$ & 11,9 a $*$ & $10 \mathrm{ab}$ & $0,68 \mathrm{c}$ & $0,20 \mathrm{a}$ \\
\hline $\mathrm{T}_{2}$ & $10,45 \mathrm{a}$ & $10 \mathrm{ab}$ & $0,37 \mathrm{a}$ & $0,23 \mathrm{c}$ \\
\hline $\mathrm{T}_{3}$ & $11,01 \mathrm{a}$ & 9 a & $0,47 \mathrm{~b}$ & $0,21 \mathrm{ab}$ \\
\hline $\mathrm{T}_{4}$ & $10,70 \mathrm{a}$ & $10 \mathrm{ab}$ & $0,48 \mathrm{~b}$ & $0,23 \mathrm{c}$ \\
\hline $\mathrm{T}_{5}^{4}$ & $11,82 \mathrm{a}$ & $12 \mathrm{~b}$ & $0,36 \mathrm{a}$ & $0,22 \mathrm{bc}$ \\
\hline $\mathrm{T}_{6}$ & $12,32 \mathrm{a}$ & $11 \mathrm{~b}$ & $0,96 \mathrm{~d}$ & $0,26 \mathrm{~d}$ \\
\hline
\end{tabular}

$\mathrm{T}_{1}$ - sem inoculação (testemunha); $\mathrm{T}_{2}$ - somente inoculação de C. candelabrum; $\mathrm{T}_{3}$ - inoculação de . candelabrum $\mathrm{x}$ Agrotrich ${ }^{\circledR}$;

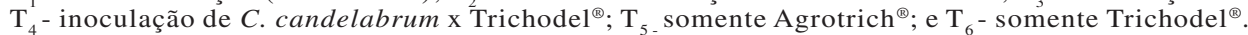

* Médias seguidas por mesma letra na coluna não diferem entre si, pelo teste de Tukey a $5 \%$ de significância.

\section{DISCUSSÃO}

As notas atribuídas no teste de confronto direto (1 a 2,5) foram classificadas por Ethur (2006), respectivamente, como muito eficiente e eficiente. A inibição do fungo Cylindrocladium spp. in vitro sob a ação do antagonista Trichoderma spp. foi testada por Santos et al. (2007). Esses autores concluíram que os isolados de Trichoderma spp., obtidos da rizosfera de goiabeira, apresentaram elevado potencial antagonista sobre Cylindrocladium spp.

Na Tabela 2, observa-se que o crescimento $(\mathrm{cm})$ de C. candelabrum, quando confrontado com os bioprotetores, foi inferior estatisticamente ao crescimento da testemunha, em que não houve confronto. Em estudo realizado por Martins-Córder e Melo (1998) foram obtidos resultados semelhantes, no confronto in vitro de isolados selvagens de Trichoderma spp. com Verticillium dahliae (causador de murcha em Solanum melongena (berinjela)). Para esses autores, essa ação antagonista do Trichoderma spp. pode estar associada à sua capacidade de produzir metabólitos voláteis e não voláteis, que atuam interrompendo o crescimento micelial do patógeno.

Na literatura são encontrados trabalhos que relatam a eficiência do Trichoderma spp. como agente antagonista a fitopatógenos. Fortes et al. (2007) estudaram a ação de isolados de Trichoderma spp. obtidos do solo, via diluição e pelo método de iscas, em confronto direto com Cylindrocladium sp. concluíram que ambos os métodos apresentaram isolados que alcançaram grau máximo (nota 1) na escala de Bell et al. (1982). Louzada et al. (2009) testaram o potencial antagonista de isolados de Trichoderma spp. originários de solos de diferentes agroecossistemas (Rio Grande do Sul, Minas Gerais, Bahia e Tocantins) no controle de Sclerotinia sclerotiorum e Fusarium solani. Entre os 230 isolados testados, 23 se mostraram eficientes no controle dos dois patógenos. Bomfim et al. (2010) destacaram uma rápida ação antagônica de Trichoderma spp. sobre Rhyzopus stolonifer com apenas $72 \mathrm{~h}$ de confronto.

Testes com folhas destacadas têm sido utilizados frequentemente, já que são eficientes e práticos para determinação do potencial dos agentes de biocontrole. Assim como neste estudo, outros autores encontraram resultados promissores com a técnica de biocontrole. Carvalho Filho (2008) selecionou isolados de Trichoderma asperellum, T. pseudokoningii, T. harzianum e $T$. atroviride para supressão de mancha-foliar causada por Cylindrocladium scoparium em mudas de eucalipto. Shiomi et al. (2006) selecionaram isolados de bactérias endofíticas dos gêneros Bacillus, Clavibacter, Cedecea e Klebsiella para controle da ferrugem (Hemileia vastatrix) em cafeeiro.

Os testes in vitro são importantes para seleção de agentes antagônicos, porém os experimentos in vivo são fundamentais para a confirmação dos resultados. Stowasser e Ferreira (1997) destacaram a eficiência do antagonista Gliocladium roseun (isolado de morangueiro) no controle da incidência de Botrytis cinerea em mudas de Eucalyptus grandis quando testado in vivo.

No experimento em viveiro, verificou-se redução nos sintomas foliares, aos 45 dias, no tratamento que recebeu a adição de Trichodel ${ }^{\circledR}$. Silva et al. (2011), testando a eficiência do Trichoderma no controle da antracnose em pepineiro, também encontraram resultados promissores (promoção do crescimento 
em até $100 \%$ e proteção contra o patógeno em até $88,39 \%$ ). Segundo esses autores, isso se deve à indução de resistência da planta, proporcionada pela aplicação do antagonista no substrato, antes da inoculação do patógeno.

A massa verde e a massa seca aumentaram quando foi acrescentado o produto à base de Trichoderma spp. $\left(\right.$ Trichodel ${ }^{\circledR}$ ). Resultados semelhantes foram obtidos com plântulas de pepino (MELO, 1996) e plantas de milho (RESENDE et al., 2004). Respostas à aplicação de Trichoderma spp. podem ser caracterizadas por aumentos significativos na porcentagem de germinação, na área foliar e na massa seca das plantas (KLEIFELD; CHET, 1992).

A altura da muda também foi superior no tratamento com apenas Trichodel $^{\circledR}$. Segundo Melo (1996), a promoção do enraizamento por fungos envolve produção de hormônios vegetais e substâncias úteis para a planta, assim como favorece a absorção e translocação de minerais, tornando o vegetal mais resistente ao ataque de patógenos.

\section{CONCLUSÃO}

O produto comercial Trichodel ${ }^{\circledR}$ para biocontrole do fungo Cylindrocladium candelabrum apresentou melhor desempenho nos testes de confronto direto e de supressão da mancha-foliar em folhas destacadas, bem como teve resultados positivos na redução dos danos causados pelo fungo em mudas de Eucalyptus saligna, no viveiro.

O isolado de Trichoderma 5D e o biocontrolador Agrotrich $^{\circledR}$ não foram eficazes nos testes com folhas destacadas de E. saligna.

Agrotrich ${ }^{\circledR}$ foi eficaz no teste de confronto direto (in vitro), porém não apresentou resultados promissores in vivo.

\section{AGRADECIMENTOS}

À Fundação de Apoio à Pesquisa do Estado do Rio Grande do Sul (FAPERGS), pelo apoio financeiro.

À Universidade Federal de Viçosa, pelo fornecimento do isolado de $C$. candelabrum utilizado neste trabalho.

À FEPAGRO - Florestas, pela disponibilização das instalações para a realização deste experimento.

\section{REFERÊNCIAS}

ALFENAS, A.C. et al. Clonagem e doenças de eucalipto. Viçosa, MG: UFV, 2004. 442 p.

BELL, D.K.; WELLS, H.D.; MARKHAM, C.R. In vitro antagonism of Trichoderma species against six fungal plant pathogens.

Phytopathology, Saint Paul, v. 72, n.4, p. 379-382, 1982.

BOMFIM, M.P. et al. O. Avaliação antagônica in vitro e in vivo de Trichoderma spp. a Rhizopus stolonifer em maracujazeiro amarelo. Summa Phytopathologica, Botucatu, v.36, n.1, p. 61-67, 2010.

CARVALHO FILHO, M. Trichoderma spp. como agentes de controle de Cylindrocladium scoparium e como promotores de crescimento em mudas de eucalipto. 2008. 86f. Dissertação (Mestrado em Fitopatologia) - Universidade de Brasília, Brasília, 2008.

CHET, I.; INBAR, J.; HADAR, I. Fungal antagonists and mycoparasites. In: WICKLOW, D. T., SODERSTROM, B. (ed.) The mycota IV: Environmental and microbial relationships. Berlin: Springer-Verlag. 1997. p. 165-184.

ETHUR, L.Z. Dinâmica populacional e ação de Trichoderma no controle de fusariose em mudas de tomateiro e pepineiro. 2006. $154 \mathrm{f}$. Tese (Doutorado em Agronomia)-Universidade Federal de Santa Maria, Santa Maria, 2006.

FERREIRA, D.F. Sisvar: versão 5.3. Lavras: UFLA, 2010.

FERREIRA, F.A. et al. Mancha de folha e desfolha do eucalipto no sudeste da Bahia causada por Cylindrocladium pteridis. Fitopatologia Brasileira, Brasília, DF, v. 17, n. 2, p. 226, 1992.

FERREIRA, E.M. et al. Eficiência de fungicidas sistêmicos para o controle de Cylindrocladium candelabrum em eucalipto. Fitopatologia Brasileira, Brasília, DF, v. 31, n.5, p. 468-475, 2006.

Revista Árvore, Viçosa-MG, v.36, n.5, p.825-832, 2012 
FORTES, F.O. et al. Promoção de enraizamento de microestacas de um clone de Eucalyptus sp. por Trichoderma spp. Revista Árvore, Viçosa, v. 31, n. 2, p. 221-228, 2007.

\section{GOMES, N.S.B.; GRIGOLETTI JR, A.; AUER, C.G.}

Seleção de antagonistas para o controle de Cylindrocladium spathulatum em erva-mate.

Boletim de Pesquisa Florestal, Colombo, n. 43, p. 123-138, 2001.

KLEIFELD, O.; CHET, I. Trichoderma: plant interaction and its effects on increased growth response. Plant soil, Dordrecht, v. 144, n. 2. p. 267-272, 1992.

LOUZADA, G.A.S. et al. Potencial antagônico de Trichoderma spp. originários de diferentes agroecossistemas contra Sclerotinia sclerotiorum e Fusarium solani. Biota Neotropica, Campinas, v.9, n.3, p.145-149, 2009.

MARTINS-CÓRDER, M.P.; MELO, I. Antagonismo in vitro de Trichoderma spp. sobre Verticillium dahliae KLEB. Scientia Agricola, Piracicaba, v. 55, n.1, p. 1-7, 1998.

MELO, I. S. Trichoderma e Gliocladium como bioprotetores de plantas. Revisão anual de patologia de plantas, Passo Fundo, v.4, p. 261-296. 1996.

NASEBY, D.C.; PASCUAL, J.A., LYNCH, J.M. Effect of biocontrol strains of Trichoderma on plant growth, Pythium ultimum populations, soil microbial communities and soil enzyme activities. Journal of Applied Microbiology, Oxford, v. 88, n.1, p. 161-169, 2000.
POLETTO, I. Nutrição, sombreamento e antagonismo biológico no controle da podridãode-raízes da erva-mate (Ilex paraguariensis $\mathrm{A}$. St.-Hill). 2008. 123 f. Dissertação (Mestrado em Engenharia Florestal) - Universidade Federal de Santa Maria, Santa Maria, 2008.

RESENDE, M.L. et al. Inoculação de sementes de milho utilizando o Trichoderma harzianum como promotor de crescimento. Ciência e

Agrotecnologia, Lavras, v. 28, n.4, p.793-798, 2004.

SANTOS, R. P. et al. Inibição do crescimento de Cylindrocladium in vitro por isolados de Trichoderma. Encontro Estudantil da Embrapa Recursos Genéticos e Biotecnologia 12. 2007, Brasília. Anais ...Brasília: Embrapa Recursos Genéticos e Biotecnologia. 2007. p. 24.

SHIOMI, H. F. et al. Bioprospecting endophytic bacteria for biological control of coffee leaf rust. Scientia Agricola, Piracicaba, v. 36, n.1, p. 32-39, 2006.

SILVA, V.N. et al. Promoção de crescimento e indução de resistência à antracnose por Trichoderma spp. em pepineiro. Pesquisa Agropecuária Brasileira, Brasília, DF, v.46, n.12, p. 1609-1618, 2011.

STOWASSER, E. S. V.; FERREIRA, F. A. Avaliação de fungos para o biocontrole de Botrytis cinerea em viveiros suspensos de eucalipto. Revista Árvore, Viçosa, v.21, n.1, p.147-153, 1997.

STRECK, E.V. et al. Solos do Rio Grande do Sul. Porto Alegre: EMATER-RS/UFGRS. Editora UFGRS. 2002. 188 p. 